\title{
Prevalence and determinants of post- traumatic stress disorder among road traffic accident survivors: a prospective survey at selected hospitals in southern Ethiopia
}

Asres Bedaso ${ }^{1,2^{*}}$, Gemechu Kediro ${ }^{1}$, Jemal Ebrahim ${ }^{1}$, Firkru Tadesse, Shewangizaw Mekonnen', Negeso Gobena ${ }^{3}$ and Ephrem Gebrehana ${ }^{4}$

\begin{abstract}
Background: Post-traumatic stress disorder (PTSD) is prevalent among road traffic accident survivors (RTA), yet the psychological welfare of the persons has largely been ignored as health care professionals focus more on managing physical injuries. Many literatures from other parts of the world have addressed the issue of posttraumatic stress disorder among road traffic accident survivors, but such studies are mostly unavailable in subSaharan Africa, especially in Ethiopia. Therefore, this study examined the prevalence and determinants of PTSD among RTA survivors attending selected hospitals in southern Ethiopia.

Methods: Institution based cross-sectional study design was employed from April 1/2018-Sep 30/2019. Data were collected from a sample of consecutively selected 423 RTA survivors through an interviewer-administered technique. A pre-tested post-traumatic stress disorder Checklist-Specific version (PCL-S) tool was used to screen PTSD. Data were entered and analysed using SPSS 22 software. A logistic regression model was fitted to identify determinants of PTSD. An adjusted odds ratio (AOR) with a 95\% confidence interval was computed to determine the level of significance with a $p$-value of less than 0.05 .

Result: A total of 416 participants were included in the study and the response rate was $98.6 \%$. The prevalence of probable PTSD among RTA survivors was $15.4 \%$ (64). After adjusting for the effects of potential confounding variables; time since accident (30-90 days) $(\mathrm{AOR}=0.33 ; 95 \% \mathrm{Cl}(0.15,0.73)$, history of previous road traffic accident $(A O R=2.67 ; 95 \% \mathrm{Cl}(1.23,5.77)$, depressive symptoms $(A O R=2.5,95 \% \mathrm{Cl}(1.10,6.10))$ and common mental disorder $(A O R=12.78,95 \% \mathrm{Cl}(5.56,29.36))$ were significant determinants of PTSD.

Conclusion: The prevalence of probable PTSD in the current study was high (15.4\%). Time since accident, history of a previous road traffic accident, having depressive symptoms and common mental disorder were significant determinants of PTSD. RTA survivors attending adult Emergency and orthopedic clinics need to be screened for PTSD and get appropriate management.
\end{abstract}

Keywords: PTSD, Prevalence, Determinants, RTA survivors, Southern Ethiopia, PCL-S

\footnotetext{
* Correspondence: asresbedaso@gmail.com; aresbedaso@gmail.com

'College of Medicine and Health Sciences, Faculty of Health Sciences, School of Nursing, Hawassa University, Hawassa, Ethiopia

${ }^{2}$ Department of public health, University of Technology Sydney, Faculty of Health, Sydney, NSW, Australia

Full list of author information is available at the end of the article
}

C C The Author(s). 2020 Open Access This article is licensed under a Creative Commons Attribution 4.0 International License, which permits use, sharing, adaptation, distribution and reproduction in any medium or format, as long as you give appropriate credit to the original author(s) and the source, provide a link to the Creative Commons licence, and indicate if changes were made. The images or other third party material in this article are included in the article's Creative Commons licence, unless indicated otherwise in a credit line to the material. If material is not included in the article's Creative Commons licence and your intended use is not permitted by statutory regulation or exceeds the permitted use, you will need to obtain permission directly from the copyright holder. To view a copy of this licence, visit http://creativecommons.org/licenses/by/4.0/. The Creative Commons Public Domain Dedication waiver (http://creativecommons.org/publicdomain/zero/1.0/) applies to the data made available in this article, unless otherwise stated in a credit line to the data. 


\section{Background}

Post-traumatic stress disorder (PTSD) is characterized by symptoms like recurrent, involuntary, and intrusive distressing memories of the traumatic event and dissociative reactions and can be diagnosed from four weeks onward [1]. The symptoms are more severe among individuals experiencing traumatic events compared to individuals experiencing non-traumatic events [2].

Globally, over 50 million people experience trauma through road traffic accidents (RTAs) every year [3]. Road traffic injuries and related deaths have turned out to be huge public health problems in the developing world, where $90 \%$ of the world's deaths due to road traffic injuries are estimated to occur $[4,5]$. Road traffic accidents (RTA) can have serious and long-lasting consequences for survivors, both in terms of physical and psychological outcomes. Different studies have shown that involvement in RTA may put individuals at increased risk for different psychiatric disorders, including posttraumatic stress disorder (PTSD), depression and anxiety [6-8]. Particularly, PTSD is now a significant public health issue among RTA survivors $[9,10]$.

The major confront after experiencing trauma is trouble in identifying persons who will shortly develop PTSD [5]. Even if most individuals exhibit PTSD symptoms in the first few weeks after a trauma, more than $50 \%$ improve without any intervention within three months [11]. It is argued that by early identification of individuals at risk of PTSD, we can give treatments in the acute post-disaster phase to prevent PTSD [12]. Based on reports from different studies, the acute stress symptoms resolve within a few weeks and a large number of patients display symptoms within 6 to 8 months after injury [13, 14].

Road traffic injury (RTI) is one of the traumatic experiences, which may lead to acute stress and posttraumatic stress disorder $[15,16]$. Currently, Road traffic accidents are a growing public health burden, especially in low and middle-income countries and estimated to be the second most important cause of disability-adjusted life years (DALYs) [16]. Mortality due to RTI in Africa is the highest in the world and there is an occurrence of 28.3 deaths per 100,000 populations $[4,17]$.

In the USA, Morbidity is mainly caused by accidents due to motor vehicles, which is the leading cause of deaths with 3.5 million reported victims annually [18]. In order to reduce this, the government closely monitors motor vehicle accidents (MVA) to prevent additional issues like a psychological problem (PTSD) other than managing the physical injury only [19]. Also, it is necessary to early diagnose the disorder and give primary care for the victims [20]. Morbidities and mortality caused by road traffic accidents are public health problems in low- income countries, especially in Ethiopia. From the year $2009 / 2010$ to $2012 / 2013$, Ethiopia has experienced a high rate of RTA death which is between the ranges of 129-145 per 10,000 vehicles [21].

European countries have reported a different number of incidence of psychiatric morbidity following a road traffic accident. A study conducted in Germany on 179 patients with injury from car accidents, showed that $18.4 \%$ of them developed PTSD [22]. Also, a crosssectional study conducted in Oyo state Nigeria $(n=$ $1105)$ the prevalence of psychiatric morbidity among RTA survivors was $21.9 \%$ [23]. Also, the prevalence of PTSD in a study conducted in Taiwan, United Kingdom, South Eastern Nigeria USA, and Kenya following car accident was estimated to be $82.2 \%$ [24], 29.1\% [25], 26.7\% [26], 51\% [27], and 13.3\% [28] respectively. A longitudinal study conducted in Bahir Dar town, Ethiopia reported an incidence of $46.5 \%$ of PTSD among RTA survivors attending the orthopedic unit [29]. Also, another facility-based cross-sectional study conducted in Addis Ababa city revealed a prevalence of $22.8 \%$ of PTSD among RTA survivors [30]. A systematic review found that the rates of PTSD among RTA survivors could range from 2 to $50 \%$ across studies [31].

Being female, low income, having the previous history of trauma, family and personal history of mental illness, the occurrence of a physical problem following injury, unemployment, presence of co-morbid psychiatric disorder and lack of social support are the major determinants of PTSD [13, 14, 26, 32-34].

PTSD could result in long-term adverse consequences if left untreated, mainly leads to social and functional impairments of RTA survivors which finally result in a poor quality of life [34]. Different studies from other parts of the world have addressed the issue of PTSD but such studies are largely unavailable in sub-Saharan Africa especially in Ethiopia. Therefore, this study examined the prevalence and determinants of PTSD among RTA survivors attending selected hospitals in southern Ethiopia. The finding could help to improve the detection and integrated management of comorbid PTSD at health facilities together with medical management.

\section{Methods}

\section{Study design and setting}

Institution based cross-sectional study design was conducted at the emergency and orthopedic department of selected hospitals in southern Ethiopia. Data were collected from five purposively selected hospitals (from 57 hospitals of all type) in the SNNP region namely; Hawassa University comprehensive specialized hospital (HUCSH), Dilla University referral hospital (DURH), Yirgalem general hospital, Shashemene referral hospital and Wolaita Sodo Christian hospital from April 1/2018- 
Sep 30/2019. The hospitals were selected based on the total number of RTA cases they managed 6 months ahead of the data collection period.

Hawassa University Comprehensive Specialized Hospital is a teaching hospital for Medical and other Health Sciences students. It is located $275 \mathrm{~km}$ south of Addis Ababa and established in 1996 E.C. It offers service at general and specialty levels including internal medicine, pediatrics and child health, general surgery, gynecology and obstetrics, ENT, neurology, neurosurgery and other services. The hospital is giving service for about 18 million people of the southern region of Ethiopia and neighboring areas of Oromia regional state. Currently, it has 350 beds for inpatient admission services.

Yirgalem general hospital is a public hospital located in Yirgalem town, Sidama zone, in the Southern, Nations, Nationalities, and Peoples Region (SNNPR). The hospital is found about $315 \mathrm{~km}$ away from the capital city Addis Ababa and inaugurated in 1966. The hospital served about 65,222 patients in 2017. It serves a catchment population of 4.2 million people, mainly from Sidama zone and other surrounding areas. The hospital is giving the service through four main departments namely: medical, surgical, pediatrics, Gynecology/Obstetrics and three special care units (Medical Intensive Care Unit, Neonatal Intensive Care Unit and Surgical recovery Room) and five clinics (Eye, Anti-retroviral Treatment, Dental, TB and MDR-TB clinics).

Dilla University Referral hospital (DURH) found in Dilla town, Gedeo zone, in the Southern, Nations, Nationalities, and Peoples Region (SNNPR) and found 360 KM away from Addis Ababa. Beyond teaching medical and other health science students, it gives inpatient and outpatient services using departments like internal medicine, pediatrics, general surgery, gynecology/obstetrics, ENT, neurology, Psychiatry, and others.

Shashemene referral hospital is established in 1943 as a leprosy control center. The hospital is found in Kuyera town about $238 \mathrm{~km}$ south of the capital city Addis Ababa, Ethiopia. Kuyera town is found near Shashemene which is the administrative center for the west Arsi zone in Oromia Region, Ethiopia. It is one of the oldest hospitals in the Oromia region serving approximately 2.1 million people living in the surrounding area. It gives inpatient and outpatient curative services through different departments.

Sodo Christian hospital is located in Sodo town and found $327 \mathrm{~km}$ South of Addis Ababa. The hospital is expected to serve around two million people. The total number of beds in the hospital was about 200. The hospital is well known for its orthopedic services having Ethiopian and foreign health professionals and it is one of 9 training sites in Africa for the Pan African Academy of Christian Surgeons.
In addition to providing surgical, medical, obstetric, and other services, all the above-mentioned hospitals are giving psychiatric service at the outpatient level. In addition to outpatient service, Dilla University referral hospital is now providing inpatient psychiatric service.

\section{Population}

All road traffic accident survivors in the southern region were considered as source population. Road traffic accident survivors attending an emergency and orthopedic department of selected public hospitals in the southern region during the study period were the study population. An individual road traffic accident survivor was the study unit.

\section{Sample size determination and sampling procedure}

Institution based cross-sectional study design was conducted at the emergency and orthopedic department of selected hospitals in southern Ethiopia. The sample size was determined by using a single population proportion formula considering different recommended assumptions $(\mathrm{Z}=$ standard normal distribution with a confidence interval of $95 \%(Z=1.96), d=0.05$ (Absolute precision, or tolerable margin of error), the anticipated population proportion $(p=50 \%)$, since no similar study conducted previously in Ethiopia, $50 \%$ was used to anticipate the proportion of the population of injured patients who experience PTSD). Adding a $10 \%$ nonresponse rate, the final sample size was 423 . Then, proportional allocation of sample size was made for the selected five hospitals.

\begin{tabular}{lll}
\hline Name of Hospital & $\begin{array}{l}\text { Allocated Sample } \\
\text { size }\end{array}$ & $\begin{array}{l}\text { Collected } \\
\text { data }\end{array}$ \\
\hline $\begin{array}{l}\text { Hawassa Univ. Comp. spec. Hospital } \\
\text { (HUCSH) }\end{array}$ & 116 & 109 \\
Shashemene General Hospital & 85 & 85 \\
Wolaita Sodo Christian hospital & 97 & 97 \\
$\begin{array}{l}\text { Dilla University referral hospital } \\
\text { (DURH) }\end{array}$ & 66 & 66 \\
Yirgalem zonal hospital & 59 & 59 \\
Total & 423 & 416 \\
\hline
\end{tabular}

\section{Data collection and measurements}

Two trained psychiatry nurses collected the data from each hospital using interviewer-administered technique. Before the actual data collection pre-test was done on $5 \%$ of the sample size to see the reliability of the tool. Injured RTA survivors attending emergency and orthopedic units of each selected hospital and who fulfill the inclusion criteria were interviewed consecutively until the sample size is met. 
Any road traffic accident survivor whose age is greater than 18 years and injured on admission for not less than one month and who are voluntary to participate in the study were included. Patients who were unable to give proper information (unconscious, severely ill and unable to communicate) and those who have no accompanying relative or informant to consent for the study were excluded.

The data collection instrument contains sociodemographic factors, clinical factors, and post-traumatic stress disorder Checklist (PCL) questionnaire. The posttraumatic stress disorder Checklist (PCL) (civilian version) assesses symptoms related to stressful experiences. The tool is a 17-item self-report measure reflecting DSM V symptoms of post-traumatic stress disorder. A symptom severity score can be obtained by summing the scores from each of the 17 items that have response options ranging from 1 "Not at all" to 5 "Extremely" [35]. Different studies examined showed that the internal consistency of the tool was above $0.75[36,37]$ and Even if the tool was not validated in Ethiopia we have conducted pretest in Adare Hospital and Cronbach alpha of 0.73 was reported. We did factor analysis to see if there is multicollinearity between items within the tool but we did not get any.

The common mental disorder was assessed using SRQ-20 whether; the respondents had experienced symptoms associated with emotional distress within 4 weeks before the interview [38]. SRQ-20 was validated in Ethiopia [39]. Depressive symptoms among RTA survivors were assessed using PHQ-9 with a 3 point severity scale over the last 2 weeks. It has demonstrated acceptable reliability and validated for use in Ethiopia. A PHQ9 score $\geq 5$ was considered as significant for meeting the symptoms of depressive symptoms [40].

To assess the family history of mental illness, respondents were asked: "Do you know a family member who had experienced a mental illness in the past or currently?" and the responses were yes/no. To examine the substance use history, respondents were asked: 'Have you ever used any substance in the last 3 months?' and the responses were yes/no. [41] Supervision was held during data collection and each questionnaire was checked for completeness by a supervisor daily. Average monthly income of study participant $<1.25$ USD per day $\left(20^{*} 1.25^{*} 30=750\right.$ ETB $)$ labelled as under extreme poverty and, $<2$ USD per day $(20 * 2 * 30=1200$ ETB per month) labelled as under poverty [42].

\section{Variables and analytical strategy}

The outcome variable for the current study is Posttraumatic stress disorder (PTSD). The independent variables include; socio-demographic characteristics (age, sex, marital status, monthly income, occupation, education level), duration since the accident, Role during the accident, history of a previous road traffic accident, presence of family or friend in the same accident, depressive symptoms, common mental disorder (CMDs), diagnosed co-morbid medical illness (Diabetes Mellitus, Hypertension, Cardiovascular disorder), substance use in the past 3 months and family history of mental illness.

Data were entered and analyzed using SPSS version 20. Logistic regression analysis was done to see the relationship between each variable with the outcome variable. Firstly, each independent variable was entered into the Bivariable logistic regression model to see its association with PTSD. Secondly, independent variables with $p<0.2$ in the Bivariable logistic regression were included in the multivariable logistic regression model to control confounding variables. During multivariable logistic regression, a $p$-value of less than 0.05 was considered statistically significant, and an adjusted odds ratio (AOR) with 95\% CI was calculated to determine the strength of association. Model fitness was checked using the Hosmer and Lemeshow test, and it was found to be 0.75 . Multi-collinearity was checked by the variance inflation factor (VIF) and tolerance.

\section{Result}

\section{Socio-demographic characteristics}

A total of 416 participants were included in the study with a response rate of $98.6 \%$, the remaining 7 excluded from the analysis because of the incomplete questionnaire. The median age of the respondents was 30 years. Among the respondents, 192 (46.2\%) were between the age range of $18-25$ years, 303 (72.8\%) were male, 217 (52.2\%) were married and 148 (34.9\%) attended secondary education. The median monthly income of the participants was 2000 ETB which ranges from 200 to 10,000 ETB (Table 1).

\section{Clinical and accident-related factors}

From the total study participants, about 50 (12\%) had depressive symptoms and 115 (27.6\%) had a common mental disorder. 104 (25\%) had a history of a previous road traffic accident and $171(41.1 \%)$ of the RTA survivors were passengers. 15 (3.6\%) had diagnosed with a co-morbid medical illness (Table 2).

\section{Substance use of the respondent's}

From the total study participants, $112(26.9 \%)$ use a substance in the past 3 months. Among the total study participants who use a substance, 34 (8.2\%) use both alcohol and Khat (Fig. 1).

\section{The prevalence of PTSD}

In the current study, the magnitude of post-traumatic stress disorder was $15.4,95 \%$ CI $(12.3-18.8 \%)$. The 
Table 1 Socio-demographic characteristics of road traffic accident survivors attending selected hospitals in southern Ethiopia, SNNPR, Ethiopia, $2019(\boldsymbol{n}=\mathbf{4 1 6})$

\begin{tabular}{|c|c|c|c|c|}
\hline S.no & Variables & Category & Frequency & Percentage \\
\hline \multirow[t]{2}{*}{1} & \multirow[t]{2}{*}{ Sex } & Male & 303 & $72.8 \%$ \\
\hline & & Female & 113 & $27.2 \%$ \\
\hline \multirow[t]{4}{*}{2} & \multirow[t]{4}{*}{ Age } & $18-25$ & 192 & $46.2 \%$ \\
\hline & & $26-35$ & 132 & $31.7 \%$ \\
\hline & & $36-45$ & 51 & $12.3 \%$ \\
\hline & & $>46$ & 41 & $9.9 \%$ \\
\hline \multirow[t]{2}{*}{3} & \multirow[t]{2}{*}{ Marital Status } & Single and Widowed & 199 & $47.8 \%$ \\
\hline & & Married & 217 & $52.2 \%$ \\
\hline \multirow[t]{4}{*}{4} & \multirow[t]{4}{*}{ Educational level } & Unable to read and write & 60 & $14.4 \%$ \\
\hline & & Primary education & 139 & $33.4 \%$ \\
\hline & & Secondary education & 145 & $34.9 \%$ \\
\hline & & College and above & 72 & $17.3 \%$ \\
\hline \multirow[t]{5}{*}{5} & \multirow[t]{5}{*}{ Ethnicity } & Oromo & 156 & $37.5 \%$ \\
\hline & & Wolaita & 64 & $15.4 \%$ \\
\hline & & Sidama & 78 & $18.8 \%$ \\
\hline & & Amhara & 33 & $7.9 \%$ \\
\hline & & Others & 85 & $20.4 \%$ \\
\hline \multirow[t]{5}{*}{6} & \multirow[t]{5}{*}{ Religion } & Orthodox & 105 & $25.2 \%$ \\
\hline & & Protestant & 197 & $47.4 \%$ \\
\hline & & Catholic & 1 & $0.2 \%$ \\
\hline & & Muslim & 109 & $26.2 \%$ \\
\hline & & Others & 4 & $1 \%$ \\
\hline \multirow[t]{7}{*}{7} & \multirow[t]{7}{*}{ Occupation } & Housewife & 32 & $7.7 \%$ \\
\hline & & Civil Servant & 55 & $13.2 \%$ \\
\hline & & Farmer & 81 & $19.5 \%$ \\
\hline & & Merchant & 68 & $16.3 \%$ \\
\hline & & Student & 94 & $22.6 \%$ \\
\hline & & Private/NGO & 48 & $11.5 \%$ \\
\hline & & Others & 38 & $9.15 \%$ \\
\hline \multirow[t]{3}{*}{8} & \multirow[t]{3}{*}{ Monthly Income } & $<750$ ETB & 45 & $10.8 \%$ \\
\hline & & 750-1250 ЕТВ & 101 & $24.3 \%$ \\
\hline & & $>1250$ ETB & 270 & $64.9 \%$ \\
\hline
\end{tabular}

prevalence of PTSD was 15.8 and $14.2 \%$ among male and female participants respectively. About 84.4 and $34.4 \%$ of participants with PTSD had a co-morbid common mental disorder (CMD) and depression respectively.

\section{Factors associated with PTSD}

After adjusting for confounding variables, multivariable logistic regression analysis revealed, time since accident (30-90 days) (AOR $=0.33$; 95\%CI $(0.15,0.73)$, history of a previous road traffic accident $(\mathrm{AOR}=2.67 ; 95 \% \mathrm{CI}$ $(1.23,5.77)$, having depression $(\mathrm{AOR}=2.5,95 \% \mathrm{CI}(1.10$,
6.10) ) and common mental disorder (CMDs) (AOR = $12.78, \quad 95 \%$ CI $(5.56,29.36))$ were significant determinants of PTSD (Table 3).

\section{Discussion}

Post-traumatic stress disorder (PTSD) is the most common psychopathology and important public health problem among survivors of a road traffic accident (RTA). The finding revealed that a high proportion of RTA survivors who attended the emergency and orthopedic unit of selected hospitals had probable PTSD (15.4, 95\% CI; 12.3-18.8). The possible reason for the 
Table 2 Clinical and accident related factors among road traffic accident survivors (RTA) attending selected hospitals in southern Ethiopia, SNNPR, Ethiopia, $2019(\mathbf{n}=\mathbf{4 1 6})$

\begin{tabular}{|c|c|c|c|c|}
\hline S.no & Variables & Category & Frequency & $\%$ \\
\hline \multirow[t]{2}{*}{1} & \multirow[t]{2}{*}{ Time since accident } & 30-90 days & 344 & $82.7 \%$ \\
\hline & & $\geq 90$ days & 72 & $17.3 \%$ \\
\hline \multirow[t]{2}{*}{2} & \multirow[t]{2}{*}{ History of Previous road traffic accident } & Yes & 104 & $25 \%$ \\
\hline & & No & 312 & $75 \%$ \\
\hline \multirow[t]{3}{*}{3} & \multirow[t]{3}{*}{ Role during accident } & Driver and assistant & 115 & $26.9 \%$ \\
\hline & & Passenger & 171 & $41.1 \%$ \\
\hline & & Pedestrian & 130 & $31.3 \%$ \\
\hline \multirow[t]{2}{*}{4} & \multirow[t]{2}{*}{ Presence of family or friend in the same accident } & Yes & 37 & $8.9 \%$ \\
\hline & & No & 379 & 91.15 \\
\hline \multirow[t]{2}{*}{5} & \multirow[t]{2}{*}{ Depressive symptoms } & Yes & 50 & $12 \%$ \\
\hline & & No & 366 & $88 \%$ \\
\hline \multirow[t]{2}{*}{6} & \multirow[t]{2}{*}{ CMDs } & Yes & 115 & $27.6 \%$ \\
\hline & & No & 301 & $72.4 \%$ \\
\hline \multirow[t]{2}{*}{7} & \multirow[t]{2}{*}{ Diagnosed Co-morbid Medical Illness } & Yes & 15 & $3.6 \%$ \\
\hline & & No & 401 & $96.4 \%$ \\
\hline \multirow[t]{4}{*}{8} & \multirow[t]{4}{*}{ Type of Diagnosed Co-morbid Medical Illness } & HTN only & 9 & $60 \%$ \\
\hline & & CVD only & 3 & $20 \%$ \\
\hline & & DM only & 2 & $13.3 \%$ \\
\hline & & $\geq 2$ of the above & 1 & $6.7 \%$ \\
\hline
\end{tabular}

Abbreviations: HTN hypertension, CVD cardiovascular disorder, DM diabetes mellitus, CMD common mental disorder

high burden of PTSD among RTA survivors in the current study might be due to inadequate psychological care in the orthopedic and emergency clinic of each hospital, severity of the trauma, delayed insurance claims and financial shortage for the RTA survivor. The prevalence of the current study was in line with the study done in Kenya 13.3\% [28].

However, the prevalence of PTSD in the current study was lower than the study conducted in Germany $18.4 \%$ [22], Taiwan 82.2\% [24], UK 29.1\% [25], South Eastern
Nigeria 26.7\% [26], USA 51\% [27], Iran 19.2\% [43], Addis Ababa, Ethiopia 22.8\% [30], Bahir Dar town, Ethiopia 46.5\% [29] and Serbian study 36\% [44]. The reason for the variation might be because of the difference in the socio-economic and geographical nature of the study area, variation in sample size, and difference in utilization of tools used to assess Posttraumatic stress disorder.

The prevalence of PTSD in the current study was higher than the prevalence of PTSD in the general

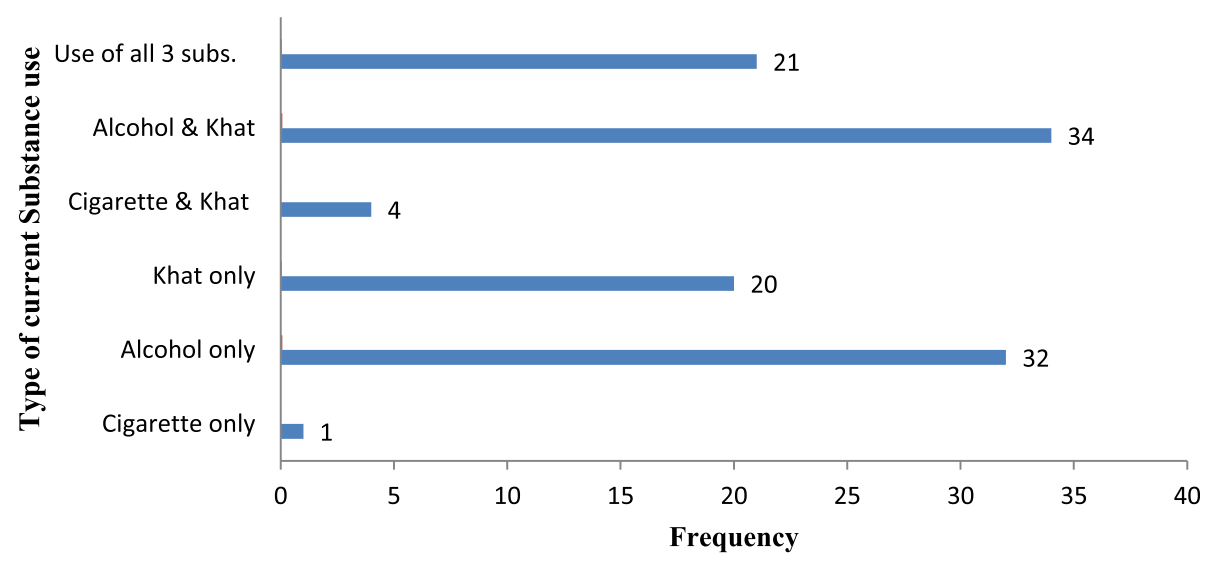

Fig. 1 Substance use of road traffic accident survivors attending selected hospitals in southern Ethiopia, SNNPR, Ethiopia, 2019 ( $\mathbf{n = 4 1 6 )}$ 
Table 3 Bivariable and multivariable logistic regression analysis of determinants of PTSD among RTA survivors attending selected hospitals in southern Ethiopia, SNNPR, Ethiopia, $2019(\mathbf{n}=\mathbf{4 1 6})$

\begin{tabular}{|c|c|c|c|c|c|}
\hline \multirow[t]{2}{*}{ Variable } & \multicolumn{2}{|c|}{ PTSD } & \multirow[t]{2}{*}{ COR $(95 \% \mathrm{Cl})$} & \multirow[t]{2}{*}{ AOR $(95 \% \mathrm{Cl})$} & \multirow[t]{2}{*}{$\boldsymbol{P}$ value } \\
\hline & No & $\overline{\text { Yes }}$ & & & \\
\hline \multicolumn{6}{|l|}{ Sex } \\
\hline Female & 97 & 16 & $0.87(0.48,1.62)$ & & \\
\hline Male & 255 & 48 & $\mathrm{RC}$ & $\mathrm{RC}$ & \\
\hline \multicolumn{6}{|l|}{ Age } \\
\hline $18-25$ & 165 & 27 & $0.68(0.28,1.62)$ & & \\
\hline $26-35$ & 113 & 19 & $0.69(0.28,1.73)$ & & \\
\hline $36-45$ & 41 & 10 & $1(0.36,2.84)$ & & \\
\hline$\geq 46$ & 33 & 8 & $\mathrm{RC}$ & $\mathrm{RC}$ & \\
\hline \multicolumn{6}{|l|}{ Marital Status } \\
\hline Single and Widowed & 168 & 31 & $1.03(0.6,1.75)$ & & \\
\hline Married & 184 & 33 & $\mathrm{RC}$ & $\mathrm{RC}$ & \\
\hline \multicolumn{6}{|l|}{ Educational level } \\
\hline Unable to read and write & 50 & 10 & $1.4(0.53,3.71)$ & $0.78(0.14,4.31)$ & 0.78 \\
\hline Primary education & 121 & 18 & $1.04(0.44,2.45)$ & $0.75(0.17,3.24)$ & 0.69 \\
\hline Secondary education & 118 & 27 & $1.6(0.71,3.61)$ & $1.42(0.36,5.63)$ & 0.62 \\
\hline College and above & 63 & 9 & $\mathrm{RC}$ & $\mathrm{RC}$ & \\
\hline \multicolumn{6}{|l|}{ Occupation } \\
\hline House wife & 25 & 7 & $\mathrm{RC}$ & $\mathrm{RC}$ & \\
\hline Civil servant & 50 & 5 & $0.35(0.1,1.24)$ & $0.38(.051,2.83)$ & 0.34 \\
\hline Farmer & 65 & 16 & $0.87(0.32,2.39)$ & $0.91(0.25,3.21)$ & 0.91 \\
\hline Merchant & 52 & 16 & $1.09(0.4,3.01)$ & $1.1(0.28,4.47)$ & 0.88 \\
\hline Student & 87 & 7 & $0.28(0.09,0.89)$ & $0.37(0.08,1.63)$ & 0.19 \\
\hline Private/NGO & 40 & 8 & $0.71(0.23,2.21)$ & $0.36(0.07,1.82)$ & 0.22 \\
\hline Others & 33 & 5 & $0.54(0.15,1.9)$ & $0.63(0.13,3.1)$ & 0.57 \\
\hline \multicolumn{6}{|l|}{ Monthly Income } \\
\hline$<750$ ETB & 40 & 5 & $0.62(0.23,1.67)$ & & \\
\hline 750-1250 ETB & 87 & 14 & $0.80(0.42,1.54)$ & & \\
\hline$>1250$ ETB & 225 & 45 & $\mathrm{RC}$ & $\mathrm{RC}$ & \\
\hline \multicolumn{6}{|l|}{ Time since accident } \\
\hline 30-90 days & 311 & 33 & $0.14(0.078,0.25)$ & $0.33(0.15,0.73)$ & $0.006^{*}$ \\
\hline$\geq 90$ days & 41 & 31 & $\mathrm{RC}$ & $\mathrm{RC}$ & \\
\hline \multicolumn{6}{|l|}{ Role during accident } \\
\hline Driver and assistant & 92 & 23 & $\mathrm{RC}$ & $\mathrm{RC}$ & \\
\hline Passenger & 147 & 24 & $1.66(0.84,3.29)$ & $0.72(0.28,1.84)$ & 0.49 \\
\hline Pedestrian & 113 & 17 & $1.08(0.55,2.11)$ & $0.63(0.22,1.77)$ & 0.38 \\
\hline \multicolumn{6}{|c|}{ History of previous road traffic accident } \\
\hline Yes & 62 & 42 & $8.9(4.97,16.01)$ & $2.67(1.23,5.77)$ & $0.013^{*}$ \\
\hline No & 290 & 22 & $\mathrm{RC}$ & $\mathrm{RC}$ & \\
\hline \multicolumn{6}{|c|}{ Presence of family or friend in the same accident } \\
\hline Yes & 33 & 4 & $0.64(0.22,1.88)$ & & \\
\hline No & 319 & 60 & $\mathrm{RC}$ & $\mathrm{RC}$ & \\
\hline
\end{tabular}

Depression 
Table 3 Bivariable and multivariable logistic regression analysis of determinants of PTSD among RTA survivors attending selected hospitals in southern Ethiopia, SNNPR, Ethiopia, $2019(\mathbf{n}=\mathbf{4 1 6})$ (Continued)

\begin{tabular}{|c|c|c|c|c|c|}
\hline \multirow[t]{2}{*}{ Variable } & \multicolumn{2}{|c|}{ PTSD } & \multirow[t]{2}{*}{ COR $(95 \% \mathrm{Cl})$} & \multirow[t]{2}{*}{ AOR $(95 \% \mathrm{Cl})$} & \multirow[t]{2}{*}{$\boldsymbol{P}$ value } \\
\hline & No & Yes & & & \\
\hline Yes & 28 & 22 & $6.06(3.18,11.54)$ & $2.58(1.10,6.10)$ & $0.029 *$ \\
\hline No & 324 & 42 & $\mathrm{RC}$ & $\mathrm{RC}$ & \\
\hline \multicolumn{6}{|l|}{ CMDs } \\
\hline Yes & 61 & 54 & $25.76(12.42,53.4)$ & $12.78(5.56,29.36)$ & $<0.001 *$ \\
\hline No & 291 & 10 & $\mathrm{RC}$ & $\mathrm{RC}$ & \\
\hline \multicolumn{6}{|c|}{ Diagnosed Co-morbid Medical IIIness } \\
\hline Yes & 13 & 2 & $0.84(0.18,3.82)$ & & \\
\hline No & 339 & 62 & $\mathrm{RC}$ & $\mathrm{RC}$ & \\
\hline \multicolumn{6}{|c|}{ Substance use in the past 3 month } \\
\hline Yes & 90 & 22 & $1.52(0.86,2.69)$ & $0.81(0.35,1.86)$ & 0.61 \\
\hline No & 262 & 42 & $\mathrm{RC}$ & $\mathrm{RC}$ & \\
\hline \multicolumn{6}{|c|}{ Family history of mental illness } \\
\hline Yes & 6 & 2 & $1.86(0.36,9.42)$ & & \\
\hline No & 346 & 62 & $\mathrm{RC}$ & $\mathrm{RC}$ & \\
\hline
\end{tabular}

population in the USA (7.8\%) [45], Australia (1.1\%) [46], Canada (9.2\%) [47] and Cape Town, South Africa (12.2\%) [32]. The possible reason for the variation might be the difference in the time point of PTSD assessment, which is in South African, the study was conducted 6 months of the post-accident period, but the current study assessed all RTA survivors from 1 month of the post-accident period.

In the current study, time since accident is significant determinants of post-traumatic stress disorder; the odds of developing PTSD among those who experienced RTA 30-90 days before data collection time were 67\% (AOR = 0.33 ; $95 \%$ CI $(0.15,0.73)$ less likely to develop PTSD compared with victims who were injured after 90 days of data collection time. The possible reason might be the decline over the course of the illness as time goes far. This is because the level of stress decreases over time and increased the chance of developing PTSD mainly explained by short duration [48]. This finding was comparable to studies conducted in California [33] and South Africa [32].

Having a history of previous road traffic accidents was also a significant determinant of post-traumatic stress disorder; the odds of developing PTSD among road traffic accident survivors who have the previous history of RTA were 2.6 times $(\mathrm{AOR}=2.67 ; 95 \%$ CI $(1.23,5.77)$ more likely to develop PTSD compared with their counterpart. This could be because having additional trauma could increase the risk of developing PTSD and other psychiatric disorders, which could also lead to deteriorated quality of life. Also, individuals who have experienced a previous road traffic accident, are more susceptible to develop PTSD. The stress of the trauma can have a cumulative effect, and a new traumatic experience can exacerbate the negative effects of previous trauma [49].

A pre-traumatic depression was also reported to be a determinant of PTSD. Those patients with depression were 2.5 times $(\mathrm{AOR}=2.5,95 \%$ CI $(1.10,6.10))$ more likely to develop PTSD compared with their counterparts. Also, having a pre-traumatic common mental disorder (CMD) was significantly associated with PTSD. Those patients with CMD were more than 12 times $(\mathrm{AOR}=12.78,95 \%$ CI $(5.56,29.36))$ more likely to develop PTSD compared with those who did not have a common mental disorder. This could be, because of having additional psychiatric disorders could increase the risk of developing PTSD and other mental illness which in turn leads to impaired functional status and decreased quality of life. Also having comorbid mental illness might interfere with a person's ability to fully process the impact of the traumatic event and their emotions about the event, which will hinder the recovery process. The finding was supported by studies conducted in South Africa, Cape Town [45], and Nigeria [26].

Over all, as it was hypothesized the burden of PTSD was high among RTA survivors attending emergency and orthopedic clinic of selected hospitals in southern region. Also, possible determinants of PTSD were identified which needs consideration while screening for PTSD among RTA survivors. 


\section{Strength and limitations}

The current study has numerous strengths. First, selection of study participants from multiple hospitals which addressed wide geographical areas of the region. Second, we used a standardized data collection tool for measuring PTSD (PCL-S). However, the study has some limitations; the tool PCL-S used to assess PTSD was screening rather than a diagnostic tool, the crosssectional nature of the study (unable to identify a causeeffect relationship), and non-random sampling technique used to select participants are the major ones.

\section{Conclusion and recommendation}

The finding in the current study revealed the prevalence of PTSD was high (15.4\%). Time since the accident (3090 days), history of a previous road traffic accident, pretrauma depressive symptoms, and common mental disorder (CMDs) were determinants of PTSD among RTA survivors.

We would like to recommend establishing a coordinated triage for prehospital transfer, psychological care in the emergency and orthopedic units, and early screening of PTSD to facilitate appropriate referral to the psychiatry clinic. Also, beyond routine screening of PTSD, ensure the availability of psychological counseling at all the trauma centers and hospitals managing RTA survivors. In long term to reduce the burden of RTA, the regional and federal government needs to set solutions for issues related to road infrastructure, implementing strict traffic rule and law enforcement mechanisms. In future longitudinal studies, have to be conducted to identify other risk factors of PTSD and better participant recruitment strategy needs to be considered.

\begin{abstract}
Abbreviations
AOR: Adjusted odds ratio; ASD: Acute stress disorder; Cl: Confidence interval; CMD: Common mental disorder; COR: Crudes odds ration; DALYs: Disability adjusted life years; DM: Diabetes Mellitus; DURH: Dilla University Referral Hospital; HUCSH: Hawassa University Comprehensive Specialized Hospital; IRB: Institutional Review Board; MINI: Mini International Neuropsychiatric Interview; OPD: Outpatient Department; PHQ-9: Patient health questionnaire; PTE: Post traumatic event; PTSD: Post traumatic stress disorder; RTA: Road traffic accident; RTI: Road traffic injury; WHO: World Health Organization
\end{abstract}

\section{Acknowledgments}

First, we would like to thank Hawassa University office of vice president for research and technology transfer for providing funding for the research. Also, we would like to thank data collectors and study participants for their unreserved effort throughout the data collection period.

\section{Authors' contributions}

$A B, G K, J E, F T, N G$, and $S M$ participated in the conception, design of the study, reviewing the proposal, and data analysis. $A B$ participated in writing the research report. $A B, G K, J E, F T, N G, S M$, and $E G$ participated in reviewing the research report. $A B$ prepared the manuscript for publication. All authors read and approved the final manuscript.

\section{Funding}

Hawassa University, Office of vice president for research and technology transfer (OVPRTT) provides financial support for payment of data collection, supervision and to buy stationeries and other office supplies.

Availability of data and materials

All relevant data are included in this article and its supporting document.

\section{Ethics approval and consent to participate}

Ethical clearance was obtained from the Institutional Review Board (IRB) of Hawassa University, college of medicine, and health sciences. Written consent was sought from individual RTA survivors attending emergency and orthopedic unit and who agreed to participate. Illiterate participants gave a fingerprint to indicate consent. Confidentiality was maintained by omitting identifiers from the data collection tool and privacy was ensured during the interview. Any participants who are not willing to participate in the study were not forced to participate. All study participants who were found to have PTSD had a detailed assessment and appropriate intervention ordered after linking with the psychiatric unit of each hospital.

\section{Consent for publication}

Not applicable.

\section{Competing interests}

The authors declare no competing interest exists.

\section{Author details}

${ }^{1}$ College of Medicine and Health Sciences, Faculty of Health Sciences, School of Nursing, Hawassa University, Hawassa, Ethiopia. ${ }^{2}$ Department of public health, University of Technology Sydney, Faculty of Health, Sydney, NSW, Australia. ${ }^{3}$ Department of Anesthesia, College of Medicine and Health Sciences, Faculty of Medicine, Hawassa University, Hawassa, Ethiopia. ${ }^{4}$ Department of Orthopedics, College of Medicine and Health Sciences, Faculty of Medicine, Hawassa University, Hawassa, Ethiopia.

Received: 19 November 2019 Accepted: 17 June 2020

Published online: 26 June 2020

\section{References}

1. Friedman MJ, Keane TM, Resick PA. Handbook of PTSD: science and practice: Guilford Press; 2007

2. Commission FRS. Nigerian traffic accidents (January to October, 2009). FRSC Report 2009.

3. Organization WH. Global status report on road safety 2013: supporting a decade of action: summary: World Health Organization; 2013.

4. Labinjo M, Juillard C, Kobusingye OC, Hyder AA. The burden of road traffic injuries in Nigeria: results of a population-based survey. Injury Prev. 2009; 15(3):157-62.

5. Hazen A, Ehiri JE. Road traffic injuries: hidden epidemic in less developed countries. J Natl Med Assoc. 2006:98(1):73.

6. Asuquo J, Edet B, Abang IE, Essien E, Osakwe O, Aigbomain E, et al. Depression and posttraumatic stress disorder among road traffic accident victims managed in a tertiary hospital in southern Nigeria. Niger J Clin Pract. 2017:20(2):170-5.

7. Razee H, van der Ploeg HP, Blignault I, Smith BJ, Bauman AE, McLean M, et al. Beliefs, barriers, social support, and environmental influences related to diabetes risk behaviours among women with a history of gestational diabetes. Health Promot J Austr. 2010;21(2):130-7.

8. Seethalakshmi R, Dhavale HS, Gawande S, Dewan M. Psychiatric morbidity following motor vehicle crashes: a pilot study from India. J Psychiatr Pract. 2006;12(6):415-8.

9. Hamanaka S, Asukai N, Kamijo Y, Hatta K, Kishimoto J, Miyaoka H. Acute stress disorder and posttraumatic stress disorder symptoms among patients severely injured in motor vehicle accidents in Japan. Gen Hosp Psychiatry. 2006;28(3):234-41.

10. Ozaltin M, Kaptanoğlu C, Aksaray G. Acute stress disorder and posttraumatic stress disorder after motor vehicle accidents. Turk psikiyatri dergisi=. Turk J Psychiatry. 2004;15(1):16-25.

11. Rothbaum BO, Foa EB, Riggs DS, Murdock T, Walsh W. A prospective examination of post-traumatic stress disorder in rape victims. J Trauma Stress. 1992;5(3):455-75. 
12. Association AP. Diagnostic and statistical manual of mental disorders (DSM$\left.5^{\oplus}\right)$ : Am Psychiatric Pub; 2013.

13. O'Donnell ML, Creamer M, Pattison P, Atkin C. Psychiatric morbidity following injury. Am J Psychiatr. 2004;161(3):507-14.

14. Mayou R, Bryant B, Duthie R. Psychiatric consequences of road traffic accidents. BMJ. 1993:307(6905):647-51.

15. Heron-Delaney M, Kenardy J, Charlton E, Matsuoka Y. A systematic review of predictors of posttraumatic stress disorder (PTSD) for adult road traffic crash survivors. Injury. 2013;44(11):1413-22.

16. Bun E. Road traffic accidents in Nigeria: a publichealth problem. Afrimedic J. 2012;3(2):34-5.

17. Ameratunga S, Hijar M, Norton R. Road-traffic injuries: confronting disparities to address a global-health problem. Lancet. 2006;367(9521):1533-40.

18. Harvey AG, Bryant RA. Acute stress disorder across trauma populations. J Nerv Ment Dis. 1999;187(7):443-6.

19. Bryant RA, Harvey AG. Gender differences in the relationship between acute stress disorder and posttraumatic stress disorder following motor vehicle accidents. Aust NZ J Psychiatry. 2003;37(2):226-9.

20. Bryant RA, Sackville T, Dang ST, Moulds M, Guthrie R. Treating acute stress disorder: an evaluation of cognitive behavior therapy and supportive counseling techniques. Am J Psychiatr. 1999;156(11):1780-6.

21. Segni G. Cause of motor vehicle accidents and possible counter measures on Addis Ababa-Shashmene roads: unpublished MA thesis: Addis Ababa University; 2007

22. Frommberger UH, Stieglitz R-D, Nyberg E, Schlickewei W, Kuner E, Berger M. Prediction of posttraumatic stress disorder by immediate reactions to trauma: a prospective study in road traffic accident victims. Eur Arch Psychiatry Clin Neurosci. 1998;248(6):316-21.

23. Amoran O, Lawoyin T, Oni O. Risk factors associated with mental illness in Oyo state, Nigeria: a community based study. Ann General Psychiatry. 2005; 4(1):19.

24. Wang CH, Tsay SL, Elaine BA. Post-traumatic stress disorder, depression, anxiety and quality of life in patients with traffic-related injuries. J Adv Nurs. 2005;52(1):22-30.

25. Stallard P, Salter E, Velleman R. Posttraumatic stress disorder following road traffic accidents. Eur Child Adolesc Psychiatry. 2004;13(3):172-8.

26. Iteke O, Bakare MO, Agomoh AO, Uwakwe R, Onwukwe JU. Road traffic accidents and posttraumatic stress disorder in an orthopedic setting in south-eastern Nigeria: a controlled study. Scand J Trauma Resusc Emerg Med. 2011;19:39.

27. Starr AJ, Smith WR, Frawley WH, Borer DS, Morgan SJ, Reinert CM, et al. Symptoms of posttraumatic stress disorder after orthopaedic trauma. JBJS. 2004;86(6):1115-21.

28. Ongecha-Owuor F, Kathuku D, Othieno C, Ndetei D. Post traumatic stress disorder among motor vehicle accident survivors attending the orthopaedic and trauma clinic at Kenyatta National Hospital, Nairobi. East Afr Med J. 2004:81(7):362-6.

29. Fekadu W, Mekonen T, Belete H, Belete A, Yohannes K. Incidence of posttraumatic stress disorder after road traffic accident. Front Psychiatry. 2019;10:519.

30. Yohannes K, Gebeyehu A, Adera T, Ayano G, Fekadu W. Prevalence and correlates of post-traumatic stress disorder among survivors of road traffic accidents in Ethiopia. Int J Ment Health Syst. 2018;12:50.

31. Haagsma JA, Polinder S, Toet H, Panneman M, Havelaar AH, Bonsel GJ, et al Beyond the neglect of psychological consequences: post-traumatic stress disorder increases the non-fatal burden of injury by more than 50\%. Injury Prevention. 2011;17(1):21-6.

32. Dickov A, Martinović-Mitrović S, Vučković N, Siladji-Mladenović D, Mitrović $D$, Jovičević $M$, et al. Psychiatric consequences of stress after a vehicle accident. Psychiatr Danub. 2009;21(4):483-9.

33. Hoskins M, Pearce J, Bethell A, Dankova L, Barbui C, Tol WA, et al. Pharmacotherapy for post-traumatic stress disorder: systematic review and meta-analysis. Br J Psychiatry. 2015;206(2):93-100.

34. Laffaye C, Cavella S, Drescher K, Rosen C. Relationships among PTSD symptoms, social support, and support source in veterans with chronic PTSD. J Trauma Stress. 2008;21(4):394-401.

35. Wilkins KC, Lang AJ, Norman SB. Synthesis of the psychometric properties of the PTSD checklist (PCL) military, civilian, and specific versions. Depression and anxiety. 2011;28(7):596-606.

36. Maselesele VM, Idemudia ES. The role of social support in the relationship between mental health and posttraumatic stress disorder amongst orthopaedic patients. curationis. 2013;36(1):1-7.
37. Chossegros L, Hours M, Charnay P, Bernard M, Fort E, Boisson D, et al. Predictive factors of chronic post-traumatic stress disorder 6 months after a road traffic accident. Accid Anal Prev. 2011;43(1):471-7.

38. Beusenberg M, Orley JH, Organization WH. A User's guide to the self reporting questionnaire (SRQ. Geneva: World Health Organization; 1994.

39. Kortmann F. Problems in practising psychiatry in Ethiopia. Ethiop Med J. 1988;26(2):77-84.

40. Manea L, Gilbody S, McMillan D. A diagnostic meta-analysis of the patient health Questionnaire-9 (PHQ-9) algorithm scoring method as a screen for depression. Gen Hosp Psychiatry. 2015;37(1):67-75.

41. Humeniuk R, Ali R, Babor TF, Farrell M, Formigoni ML, Jittiwutikarn J, et al. Validation of the alcohol, smoking and substance involvement screening test (ASSIST). Addiction. 2008;103(6):1039-47.

42. World Bank. Country and lending groups: Low-income economies. 2014. [Cited 2013 March 5]. Available: http://data.worldbank.org/about/ countryclassifications/country-and-lend. Accessed 10 June 2020.

43. Sadat Z, Abdi M, Aghajani M. Prevalence of posttraumatic stress disorder and related factors among patients discharged from critical care units in Kashan, Iran. Arch Trauma Res. 2015;4(4):1-6.

44. Saberi $\mathrm{H}$, Abbasian $\mathrm{H}$, Kashani MM, Esfahani AN. Post-traumatic stress disorder: A neglected health concern among commercial motor vehicle drivers. Int J Occup Environ Med. 2013:4:313-185-94.

45. Kessler RC, Sonnega A, Bromet E, Hughes M, Nelson CB. Posttraumatic stress disorder in the National Comorbidity Survey. Arch Gen Psychiatry. 1995; 52(12):1048-60.

46. Creamer M, Burgess P, McFarlane A. Post-traumatic stress disorder: findings from the Australian National Survey of mental health and well-being. Psychol Med. 2001;31(7):1237-47.

47. Van Ameringen $M$, editor Posttraumatic stress disorder in Canada: An epidemiological study. Paper to be presented in March, 2004 at the 24th Annual Conference of the Anxiety Disorders Association of America, Miami, Florida Obtained from the internet on; 2003.

48. Mason S, Wardrope J, Turpin G, Rowlands A. The psychological burden of injury: an 18 month prospective cohort study. Emerg Med J. 2002; 19(5):400-4.

49. Post-traumatic stress disorder. Family Doctor-American Academy of Family Physicians website. Available at: https://familydoctor.org/condition/posttraumatic-stress-disorder. Updated June 2017. Accessed June 10, 2020.

\section{Publisher's Note}

Springer Nature remains neutral with regard to jurisdictional claims in published maps and institutional affiliations.

\section{Ready to submit your research? Choose BMC and benefit from:}

- fast, convenient online submission

- thorough peer review by experienced researchers in your field

- rapid publication on acceptance

- support for research data, including large and complex data types

- gold Open Access which fosters wider collaboration and increased citations

- maximum visibility for your research: over $100 \mathrm{M}$ website views per year

At $\mathrm{BMC}$, research is always in progress.

Learn more biomedcentral.com/submission 